\section{Identification of inorganic compounds in eggshell as a dental remineralization material}

\author{
Asmawati
}

CrossMark

\title{
Abstract
}

Objective: Many patients suffer from sensitive teeth after bleaching that can cause demineralization of enamel and widening of dentinal tubules. Hence, researchers are looking for natural ingredients for enamel re-mineralization material, including chicken egg shell, because it contains calcium carbonate that can restore lost inorganic compounds. This study aimed to identify the inorganic compounds in eggshell used as dental remineralization agent.

Material and Methods: This study is a laboratory experiment with post-test-only control-group design. The research sample comprised five maxillary central incisors over which 35\% hydrogen peroxide bleaching material was applied in different time durations: 1 hour, 1 hour and 30 minutes, 2 hours, 2 hours and 30 minutes and 3 hours. Then, samples were applied with chicken egg shell gel for 14 consecutive days. Analysis was conducted to identify inorganic compounds using Energy Dispersive X-ray Spectroscopy (EDS).

Results: The application of chicken egg shells gel does not cause a significant difference in the composition of enamel compound between the control and treatment groups.

Conclusions: There is an increasing number of inorganic compounds in the samples that received a coating of eggshell gel, such as calcium, phosphorus, magnesium, chlorine, oxygen, and aluminum.
Department of Oral Biology, Faculty of Dentistry, University of Hasanuddin, Makassar, Indonesia

*Corresponding to: Asmawati, Department of Oral Biology, Faculty of Dentistry, University of Hasanuddin, Makassar, Indonesia

Received: 25 0ctober 2017 Revised: 1 November 2017 Accepted: 16 November 2017 Available online: 1 December 2017

Keywords: Eggshells gel, Enamel compound, Identification

Cite this Article: Asmawati. 2017. Identification of inorganic compounds in eggshell as a dental remineralization material. Journal of Dentomaxillofacial Science 2(3): 168-171. D0I: 10.15562/jdmfs.v2i3.622

\section{Introduction}

Nowadays, appearance is one of the things that people pay attention to, especially those who are involved in the field of entertainment, such as models, movie stars and singers as well as those who work in the field that demands attractive appearance, like a newsreader, teacher, or stewardess. ${ }^{1,2}$ White teeth is one thing that supports appearance. Tooth whitening, better known as dental bleaching, is a common bleaching procedure to restore tooth color to the original color by using chemicals whose primary purpose is to restore a person's aesthetic appearance. ${ }^{1,3}$ There are several kinds of teeth-whitening agents that have been used, such as sodium hypochlorite, sodium perborate and hydrogen peroxide..$^{2-3}$

The most commonly used tooth-whitening agent is $35 \%$ hydrogen peroxide. Hydrogen peroxide is a clear, colorless, odorless and non-flammable compound. A change that takes place in the enamel structure after bleaching treatment is dental erosion. Concentration of teeth-whitening agents and dental exposure is a greater risk of dental sensitivity. At this time, many materials are being produced to improve the remineralization process. In addition to fluorite, Casein Phosphopeptide-Amorphous Calcium Phosphate (CPP-ACP), chicken egg shell can also improve the process of remineralization..$^{2-3}$

The eggshell is the greatest source of $\mathrm{CaCO} 3$ (calcium carbonate) with a 95\% concentration.
One alternative is to process the egg shell into a hydroxyapatite powder. Hydroxyapatite is a term used to describe a bond containing calcium ions that can be combined with orthophosphates, phyrophosphates, hydrogen or hydroxides that are the main ingredients in bone formation and tooth enamel, so-called biomaterials. ${ }^{3,4}$ The main composition of eggshell is calcite, the crystalline form of calcium carbonate $(\mathrm{CaCo} 3)$. The average weight of an eggshell is about 5 grams and $40 \%$ of the egg shells is made up of calcium. ${ }^{5}$

The presence of high calcium oxide $(\mathrm{CaO})$ in eggshells is expected to enhance the remineralization process. To observe this remineralization process, we used Energy Dispersive X-ray Spectroscopy (EDS) because EDS has the advantage of determining elemental power in samples ranging from beryllium to detectable uranium. Based on the above description, the authors wanted to know enamel remineralization after application of egg shell gel using EDS. The purpose of this study was to identify inorganic compounds in eggshells as a dental remineralization agent.

\section{Material and methods}

This study was a laboratory-based experiment with post-test-only control-group design. This study was conducted in the Laboratory of Microstructures 
Faculty of Science University of Makassar. The study sample comprised post-extracted maxillary central incisors.

The synthesis of hydroxyapatite from eggshell eggs begins with calcination of chicken egg shell powder at a temperature of $1000^{\circ} \mathrm{C}$ for 5 hours. The calcined $\mathrm{CaO}$ was suspended in $1000 \mathrm{ml}$ of aquades with a $0.5 \mathrm{M}$ concentration of $\mathrm{Ca}$ (calcium). After that, a $100-\mathrm{ml}(\mathrm{NH} 4)$ 0.3M HPO4 solution was poured drop by drop into the $\mathrm{CaO}$ suspension at $40^{\circ} \mathrm{C}$ while the solution was stirred using a magnetic stirrer and left for 5 hours. Subsequently, sintering was performed on dry precipitates to obtain Ca10 (PO 4) $6(\mathrm{OH} 2)$ compounds at $800^{\circ} \mathrm{C}$ for 1 hour. ${ }^{6}$

The chicken eggshell gel preparation was started by inserting 0.4 grams of carbopol into the mortar and $9.82 \mathrm{ml}$ of distilled water was added to the mixture and the mixture was stirred rapidly until the solution was clear; then $0.56 \mathrm{ml}$ of $10 \% \mathrm{NaOH}$ solution was added and the mixture was stirred in order to obtain a gel-like mass. Nipagin $0.02 \mathrm{~g}$ was dissolved into $96 \%$ ethanol and put into the gel basin. A quantity of 2.8 grams of hydroxyapatite powder was added to a gel-shaped basement and stirred until homogeneous. ${ }^{7}$

Five post-extracted maxillary central incisors were stored in saline solution to prevent tooth decay. Dental crown from the calculus and debris were cleaned using pumice. Samples were twice-rinsed

Table 1 Inorganic compounds on dental enamel after the application of egg shell gel

\begin{tabular}{lcc}
\hline \multirow{2}{*}{ Enamel Compounds } & EDS & Comparative test \\
\cline { 2 - 3 } & Mean \pm SD & p-value \\
\hline Oxygen & $14.292 \pm 0.26224$ & \\
Sodium & $0.358 \pm 0.070143$ & \\
Calcium & $3.302 \pm 0.060992$ & \\
Phosphorus & $2.11 \pm 0.4062$ & 0.987 \\
Potassium & $0.135 \pm 0.007071$ & \\
Magnesium & $3.764 \pm 6.253326$ & \\
Aluminum & $0.4 \pm 0.007071$ & \\
Chlorine & $0.14 \pm 0.01$ & \\
\hline
\end{tabular}

in running water. Samples were separated using tweezers and later dried with water blow. After drying, the sample was cut using a carborundum disc in the cemento enamel junction area measuring $3 \times 3 \mathrm{~mm}$ size. Bleaching material of $35 \%$ hydrogen peroxide were then applied over the samples within time durations of 1 hour, 1 hour and 30 minutes, 2 hours, 2 hours and 30 minutes and 3 hours. Later, the sample was washed using normal saline solution for the application of chicken egg shell gel. The sample then was smeared with chicken egg shell gel for 14 days where reapplying was done every 24 hours and later rinsed using saline solution. On day 14 , the sample was washed using saline solution until it was clean and analyzed using Energy Dispersive X-Ray Spectroscopy (EDS).

\section{Results}

Identification of inorganic compound was carried out with EDS.

Figure 1 after application of eggshell gel, it could be seen on EDS examination that there were inorganic compounds produced by eggshell gel after 1 hour application: oxygen, sodium, calcium, phosphorus, potassium, magnesium, aluminum, and chlorine. The inorganic compound that showed the highest diffraction pattern is calcium and the lowest is chlorine.

Figure 2 after application of eggshell gel, it could be seen on EDS examination that there were inorganic compounds produced by eggshell gel after 1 hour 30 minutes, and the compounds detected include: oxygen, sodium, calcium, phosphorus, potassium, magnesium, aluminum, and chlorine, with calcium being the inorganic compound with the highest diffraction pattern and chlorine the lowest.

Figure 3 after application of eggshell gel, it could be seen on EDS examination that there were inorganic compounds produced by eggshell gel after 2 hour application, which include: oxygen, sodium, calcium, phosphorus, potassium, magnesium, aluminum; the inorganic compound with

Table 2 Composition of dental enamel after the application of chicken egg shell gel

\begin{tabular}{|c|c|c|c|c|c|c|c|c|}
\hline Enamel Composition Group & Oxygen & Sodium & Calcium & Phosphorus & Potassium & Chlorine & Magnesium & Result \\
\hline Hydrogen Peroxide 1 hour & 15.78 & 1.31 & 3.39 & 2.13 & 1.13 & 2.15 & 1.16 & Significant \\
\hline $\begin{array}{l}\text { Hydrogen Peroxide } 1 \text { hour } \\
30 \text { minutes }\end{array}$ & 15.10 & 1.47 & 3.39 & 3.19 & 3.14 & 0.13 & 0.21 & Significant \\
\hline Hydrogen Peroxide 2 hour & 15.29 & 0.35 & 3.27 & 3.29 & 2.11 & 0.13 & 0.15 & Significant \\
\hline $\begin{array}{l}\text { Hydrogen Peroxide } 2 \text { hour } \\
30 \text { minutes }\end{array}$ & 12.94 & 0.28 & 3.13 & 2.1 & 3.28 & 0.15 & 0.18 & Significant \\
\hline Hydrogen Peroxide 3 hour & 11.27 & 0.26 & 3.33 & 1.09 & - & 0.14 & 0.15 & Not significant \\
\hline
\end{tabular}




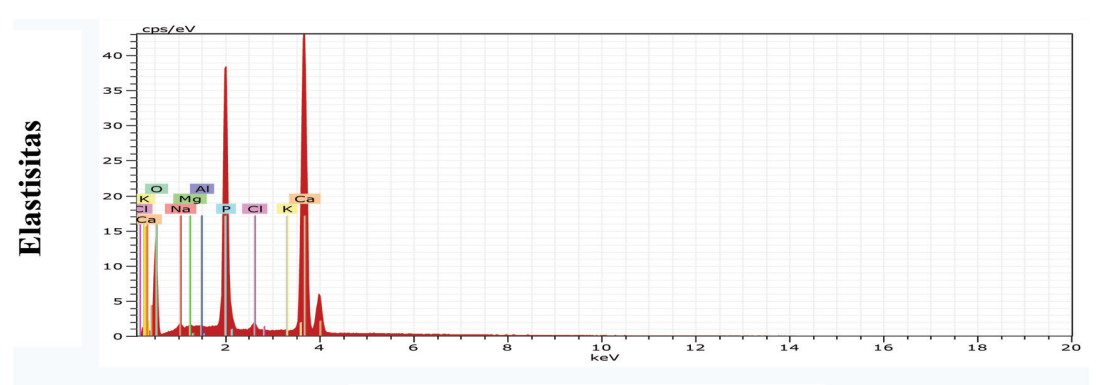

Tension

Figure 1 X-ray diffraction pattern of dental enamel after the application of chicken egg shells gel over incisors for 1 hour

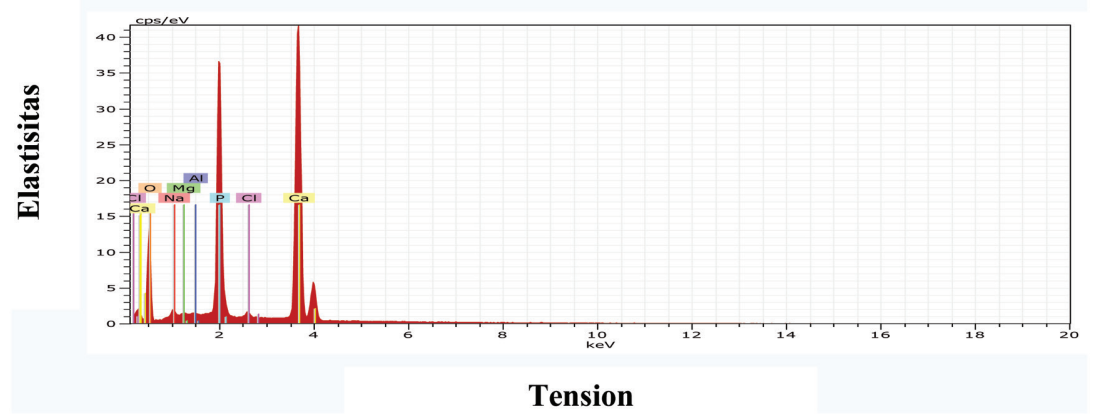

Figure 2 X-ray diffraction pattern of dental enamel after the application of chicken egg shells gel for a period of 1 hour and 30 minutes

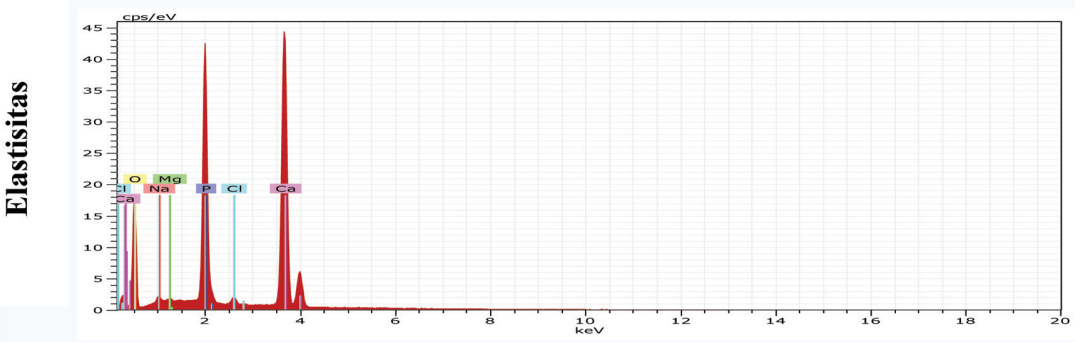

Tension

Figure 3 X-ray diffraction pattern of dental enamel after the application of chicken egg shell gel for 2 hours

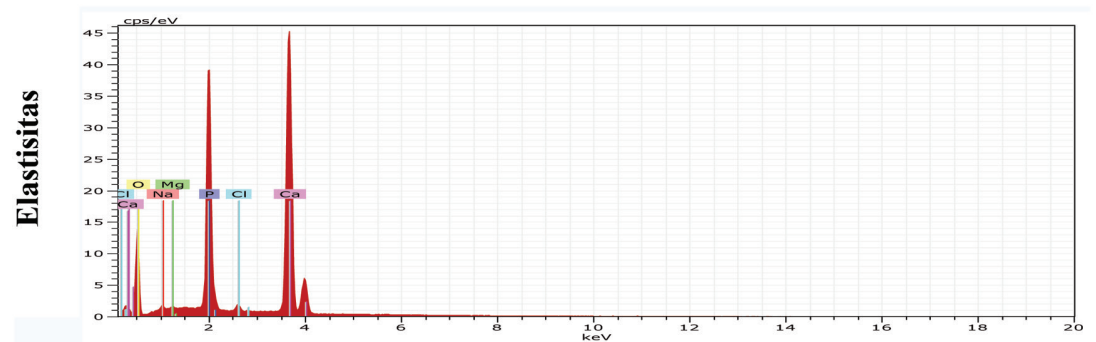

Tension

Figure 4 X-ray diffraction pattern of dental enamel after the application of chicken egg shells gel for 2 hours and 30 minutes the highest diffraction pattern is calcium, and the lowest is chlorine.

Figure 4 after the application of eggshell gel, it could be seen on EDS examination that there were inorganic compounds produced by eggshell gel application after 2 hour 30 minutes, and the compounds identified include: oxygen, sodium, calcium, phosphorus, potassium, magnesium, aluminum and chlorine; the inorganic compound that showed the highest diffraction pattern was calcium and the lowest was chlorine.

From table 1, it can be seen that the average composition of oxygen in each treatment was 14.292; average composition of sodium, 0.358; calcium, 3.302; phosphorus, 2.11, potassium, 0.135; magnesium, 3,764; aluminum, 0.4; chlorine, 0.14; we could see the average composition of inorganic compound after chicken egg shells gel application with $p$ value $0.987>0.05$, which means that "chicken egg shells gel application on dental enamel surface creates a significant influence on dental enamel surface"

Table 2 shows the composition of enamel from EDS, which is marked by the increasing value of oxygen, sodium, calcium, potassium, chlorine, and magnesium, except for the application in the time duration of 3 hours.

\section{Discussion}

This study was a laboratory experiment conducted to identify inorganic compounds in chicken egg shell by using EDS. The samples used in this study were 5 upper-central incisors that were coated with dental bleaching material, hydrogen peroxide $35 \%$, within the time range of 1 hour, 1 hour and 30 minutes, 2 hours, 2 hours and 30 minutes, and 3 hours. Then, samples were coated with chicken egg shells gel for 14 consecutive days. ${ }^{7,8}$

Inorganic compounds found in each sample include: calcium, sodium, oxygen, phosphorus, potassium, magnesium, aluminum and chlorine in different proportions. This is because each compound goes through spontaneous precipitation in the remineralization agent (chicken egg shells gel) and there are several compounds that are insoluble in water, such as phosphate, whereas calcium, a class of alkaline, is less reactive and difficult to dissolve; in addition, differences in dental enamel thickness causes different depths of penetration of each inorganic compound. This is in line with other studies suggesting that the thickness of dental enamel affects the penetration of inorganic compound. ${ }^{6,7}$ 
Remineralization can occur if the $\mathrm{pH}$ is neutral and there is enough $\mathrm{Ca} 2+$ and $\mathrm{PO} 43-$ in the environment. Calcium and phosphate ions will hinder the decomposition process of hydroxyapatite and cause rebuilding or reconstruction of partially soluble crystalline hydroxyapatite. Remineralization is the natural repair process to restore lost minerals in the ionic form of hydroxyapatite mineral and it leads to loss of ion calcium, phosphate and fluoride ions that will be replaced with fluorapatite. Ion is more resistant to acids; therefore, apatite crystals in enamel surface that has been remineralized are more resistant to organic acids. This lasts until the oral $\mathrm{pH}$ comes down to normal levels. In contrast, when $\mathrm{pH}$ in oral cavity increases, calcium, minerals, phosphate and fluoride ions in the form of fluorap-atite will return to the tooth structure to blend and form a larger hexagonal crystal. This is also in line with the results of study conducted by Bejoy Mony et al. who stated that high $\mathrm{pH}$ and calcium are important in the remineralization process. ${ }^{9,10-14}$

Ions of calcium and phosphorus will increase hydroxyapatite's saturation level. Saturation level is affected by the concentration of calcium in the enamel surrounding environment. The higher the concentration of calcium and phosphorus in the environment, the higher the saturation level of hydroxyapatite. ${ }^{8}$ Concentration of calcium and phosphates results in rapid precipitation of minerals in enamel microporosity. Precipitation of calcium and phosphate mineral results in the closure of microporosity enamel, and this is what we call enamel remineralization. ${ }^{11,13}$

\section{Conclusion}

There is an increasing number of inorganic compounds in samples that were coated with eggs hell gel, such as calcium, phosphorus, magnesium, chlorine, oxygen, aluminum and they play an important role in the remineralization process.

\section{Conflict of Interest}

The author report no conflict of interest.

\section{References}

1. Noh CT, Syafriadi M. Pengukuran kadar kalsium saliva terlarut pada gigi yang dilakukan ekternal bleaching dan dipapar dengan streptococcus mutans. Jurnal PDGI 2014;2: 63-64.

2. Fauziah C, Fitriyani S, Diansari V. Colour change of enamel after application of averrhoa bilimb. J Dent Indo 2012;3: 53-54.

3. Meizarini A, Rianti D. Tooth bleaching material with ADA/ISO certificate. Maj Ked Gigi (Dent J) 2005;2: 73-75.

4. Dahlan K, Prasetyanni F, Sari YW. Sintesis hidroksiapatit dari cangkang telur menggunakan drymetode. Biofisika 2009;5: 71-78.

5. Abdulrahman, Idris., Tijani, Ebeyeye Hamzat. From garbage to biomaterials: An overview on egg shell based hydroxyapatite. J Materials 2014; 1-6.

6. Wardani SN, Fadli A, Irdoni. Sintesis hidroksiapatit dari cangkang telur yaam dengan metode presipitasi. JOM FTEKNIK 2015;2: 1-6.

7. Cardenas MJ, Cantu GF, Rodriguez OR, et al. Concentration and distribution of trace elements in dental enamel using the enefgy dispersive $\mathrm{x}$-ray spectroscopy technique. European Scientific Journal 2014;10: 293-294.

8. E Ibrahim-Auerkari., A Soufyan., F Alkatiri. Effect of Xylitol on Remineralization of Demineralized Dental Enamel. Int J Clin Prev Dent 2010;6.

9. Hincke TM, Nys Y, Gautron J, et al. The eggshell: structure, composition and mineralization. Frontiers in Bioscience 1268-1269.

10. HatimA, Nadira, Ahmad M, et al. A novel method for conversion of eggshell hydroxyapatite particles to nanosize using microwave irradiation. IJERSTE 2013;2:71-76.

11. Hamagaran G, Meelakantan P. Remineralization of the tooth structure- the future of dentistry. Int J PharmTech Res 2014;6: 487-483.

12. Godoy, Franklin G, Hicks, et al. Mantaining the integrity of enamel surface. JAm Dent Assoc 2008;139: 25s- 34s.

13. Cury, Jaime A, Tenuta, et al. Enamel remineralization: controlling the caries disease or treting early caries lesions. J Braz Oral Health 2009;23: 23-30.

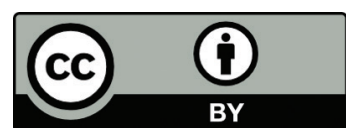

This work is licensed under a Creative Commons Attribution 